\title{
Itinerários da Educação Básica no Ensino Fundamental II no Conteúdo Curricular de Geografia: da Constituição Federal de 1988 à prática esperada da BNCC
}

\author{
Itineraries of Basic Education in Elementary School in the Curricular Content of \\ Geography: from the Federal Constitution of 1988 to the expected practice of BNCC
}

\begin{abstract}
Itinerarios de Educación Básica en la Escuela Primaria en el Contenido Curricular de la Geografía: desde la Constitución Federal de 1988 hasta la práctica esperada de BNCC
\end{abstract}

\author{
Marcia Batista Lanes ${ }^{1}$ \\ https://orcid.org/0000-0002-1133-7034
}

\begin{abstract}
RESUMO: No artigo, apresentam-se e discutem-se os PCN, principal referencial para o currículo do Ensino Fundamental até a entrada em vigor da BNCC, a fim de analisar e compreender como se deram as políticas curriculares, assim como a prática curricular era orientada em sala de aula, no ensino de Geografia para o 6 ano do Ensino Fundamental II. Esse estudo se baseia na metodologia da análise do conteúdo em dois livros didáticos desta série. Adotou-se essa sistemática de análise para aferir como estes apresentavam o conceito de território e suas variáveis, considerados fundantes nos estudos geográficos, uma vez que preconizavam os PCN a importância destes para a Geografia, ao longo da Educação Básica, assim como também a opção teórico-metodológica dos autores dos livros analisados, frente ao materialismo ou ao simbolismo geográfico. Conclui-se que as práticas curriculares anteriores à BNCC nos revelam autores que seguiam determinações próprias ao escreverem livros, ignorando os orientadores de currículos, justificadas por formações voltadas ao materialismo geográfico, em detrimento do simbolismo ao qual a Geografia também se propõe.
\end{abstract}

PALAVRAS-CHAVE: Educação básica. Ensino de Geografia. Constituição Federal. BNCC.

\begin{abstract}
The PCNs were the main reference used to assemble the curriculum of Elementary Education before the implementation of BNCC and, in this present paper, are presented and discussed in order to analyze and comprehend how curricular policies took place, as well as how curricular practice was guided inside the classroom in geography classes taught to students of the 6th year of Elementary School II. This study was based on the methodology of content analysis of two textbook used for the 6th grade. This systematic analysis was adopted to assess how those books presented the concept of territory and its variables, which are considered fundamental for geographic studies, once the PCNs stated its importance for Geography throughout basic education, and also the theoretical-methodological option of the authors of the analyzed books, regarding materialism or geographic symbolism. The present study concludes that the curricular practices before the BNCC
\end{abstract}

\footnotetext{
1 Mestre em Gestão Integrada de Território (UNIVALE). Professora da Faculdade PitágorasGovernador Valadares. E-mail: marcialanes2010@gmail.com.
} 
reveal authors who followed their own determinations when writing books, ignoring the curriculum guides, justified by formations focused on geographical materialism, to the detriment of the symbolism to which Geography also proposes itself.

KEYWORDS: Basic education. Geography teaching. Federal Constitution. BNCC.

RESUMEN: En el artículo, se presentan y se discuten los PCN, la referencia principal para el plan de estudios de la Enseñanza Fundamental hasta la entrada en vigor del BNCC, con la finalidad de analizar y comprender cómo se llevaron a cabo las políticas curriculares, así como la práctica curricular era orientada en el aula, en la enseñanza de Geografía para el sexto año de la Enseñanza Fundamental II. Ese estudio se basa en la metodología de análisis de contenido en dos libros didácticos de esa serie. Fue adoptado ese análisis sistemático para evaluar cómo ellos presentaban el concepto de territorio y sus variables, considerados fundamentales en los estudios geográficos, una vez que recomiendan los PCN la importancia de ellos para la Geografía, a lo largo de la Educación Básica, así como la opción teórico-metodológica de los autores de los libros analizados, frente al materialismo o al simbolismo geográfico. Resulta que las prácticas curriculares anteriores al BNCC revelan autores que siguieron sus propias determinaciones al escribieren libros, ignorando las guías curriculares, justificadas por formaciones enfocadas en el materialismo geográfico, en detrimento del simbolismo a lo cual la Geografía también se propone.

PALABRAS CLAVE: Educación básica. Enseñanza de Geografía. Constitución Federal. BNCC.

\section{INTRODUÇÃO}

O presente artigo é o resultado da pesquisa de mestrado do curso de Gestão Integrada do Território, da Universidade Vale do Rio Doce, MG, cujo objetivo consistiu em analisar dois livros didáticos de Geografia do 6ํano do Ensino Fundamental II, sendo estes Projeto Araribá Plus de Geografia para o 6a ano, Editora Moderna, 2014, sem autores, identificados como obra coletiva e Projeto Athos 6ำ ano, também datada a sua edição de 2014, das autoras Sonia Castellar e Ana Paula Saferian e confrontá-los quanto ao ensino do conceito de território e suas variáveis, como territorialidade, presentes nos PCN Parâmetros Curriculares Nacionais, enquanto referenciais curriculares em 2014 e a quase completa ausência deste conceito nas referidas obras didáticas.

Analisamos e discutimos o que se entendia por currículo nacional antes da homologação da BNCC - Base Nacional Comum Curricular, do Ensino Fundamental, destacando a parte II deste nível de ensino, mais especificamente no 6ํano.

A análise de dois livros didáticos da referida série, no conteúdo curricular de Geografia, proporcionaram a discussão acerca do entendimento das políticas educacionais que compuseram o currículo até a homologação da BNCC, destacando o ponto de vista dos autores, que seguiam a orientação que Ihes parecia lógica e a expectativa dos professores em relação ao que seria entendido como Currículo, no contexto histórico precedente à homologação da BNCC em 2017, o que, quase invariavelmente, era livresca, ou seja: currículo seria o sumário dos livros. 
O desenvolvimento deste estudo foi baseado na análise do conteúdo dos referidos livros didáticos, a partir do qual ficou evidenciada as contradições entre os dispositivos legais curriculares anteriores a 2017, quando é homologada a BNCC do Ensino Fundamental, e o produto oferecido aos estudantes, o livro didático propriamente dito, deste período.

Autores de renome nacional, veteranos na escrita de materiais didáticos, desde o final da década de 1980 ofereciam livros cujos currículos não se apresentavam em conformidade com as orientações curriculares, embora até pudessem fazer isso, na ausência da BNCC.

A partir da análise de documentos legais relacionados às prescrições do ainda não concluso referencial do currículo nacional, em 2017, anteriormente à homologação da BNCC, e ao que viria a embasar o pretenso currículo oficial, nos baseamos nas prescrições das duas maiores leis educacionais brasileiras: a Constituição Federal de 1988 e a LDB Lei de Diretrizes e Bases, Lei 9394 de 1996, assim como nos PCN - Parâmetros Curriculares Nacionais, exclusivos para o Ensino Fundamental de oito anos à época, considerados referenciais para o currículo da Educação Fundamental II nesse momento, mas este último, ressaltamos, sem o efeito de lei. (BRASIL, 1988, 1996, 1998).

Esses documentos são hierarquicamente citados nesta pesquisa, ressaltamos que tais leis/referências são fundamentais para nortear a Educação Básica brasileira, em especial na fase Fundamental II, destacadamente no $6^{\circ}$ ano, objeto desta análise de livros, em busca do objetivo de apontar como o conceito de território era trabalhado nessa série específica, uma vez que os PCN referenciam que é conceito fundante para a compreensão do espectro geográfico, ao longo da evolução do estudante, até que este complete o Ensino Médio, uma vez que o fará compreender as relações deste, por exemplo, com o Poder constituído ou não.

Os PCN receberam destaque, pois constituíram-se como documentos essenciais norteadores do ensino na Educação Fundamental, no sentido de amparar o que se compreendia de currículo, antes da entrada em vigor da BNCC.

A área de pesquisa é o ensino de Geografia na Educação Básica, destacando o 6ํㅜㅇ ano da fase Fundamental II e o objetivo principal é relacionar as orientações dos PCN ao currículo praticado em conteúdo curricular (matéria/disciplina em linguajar informal da escola) de Geografia, através de análise de conteúdo de livros didáticos desta série escolar, anteriormente nomeados.

\section{EDUCAÇÃO FUNDAMENTAL II, POLÍTICAS E PRESCRIÇÕES LEGAIS}

A Constituição Federal de 1988 é o marco referencial de transformações e melhorias na educação nacional em seu histórico recente, funcionando, na prática, como a principal 
prescritora de políticas educacionais nacionais. Portanto, derivam da Constituição Federal de 1988 a LDB n. 9.394/1996, decretos, resoluções e, pareceres, que definem a estrutura legal da educação brasileira.

Essa legislação que deriva da Constituição Federal é chamada de Lei Complementar, pois complementa as normas institucionais. A Lei Complementar foi introduzida na hierarquia da legislação brasileira após a Constituição de 1967 e tem sido usada com maior frequência após a Constituição Federal de 1988 (PINTO; PIZZIRANI, 2017).

No cotidiano escolar, a proposta pedagógica, segundo Kramer (1997, p. 21), dinâmica e sem verdades absolutas, traduziria um projeto político de sociedade, estando nela implícita, portanto, um conceito de cidadania e, segundo esta autora:

Uma proposta pedagógica é um caminho, não é um lugar. Toda proposta pedagógica é construída no caminho, no caminhar. Toda proposta pedagógica é uma história que precisa ser contada. Toda proposta pedagógica tem uma aposta a mais [...]. Uma aposta porque, sendo parte de uma dada política pública, contém um projeto político de sociedade e um conceito de cidadania, de educação e de cultura.

Logo, ao se caminhar pela via das propostas pedagógicas, vai se pavimentando esta estrada com o deslocamento na direção da educação que gera cidadania e cultura, assim como a educação definindo a direção do currículo, entendido como um projeto em construção permanente, um "território em disputa" (ARROYO, 2014) incessante e em aberto, que se configurará como o andamento, finalidade e a direção a ser seguida por este imprescindível instrumento de formatação do direcionamento educacional.

Antes, as discussões eram restritivas aos setores institucionais e a população, assim como os principais interessados, os estudantes, estavam invariavelmente de fora dos debates acerca das questões curriculares, até mesmo porque o que estava na pauta era 0 ufanismo e a defesa nacional centradas na luta antissocialista imposta pelo regime militar e seu temor, típico da era da guerra fria, que durou longos 21 anos.

Entretanto, a redemocratização do Brasil, em 1988, com a consequente promulgação da Constituição Federal, abriu novas possibilidades para as discussões acerca de assuntos até então espinhosos como cidadania, justiça social, educação para todos e inclusão educacional, entre outros, assim como a educação passou a ser dever da família e do Estado, em parceria, proporcionando maior abertura às discussões escolares, ainda anteriores às discussões acerca do currículo.

Um Estado redemocratizado estaria, em tese, pronto para discutir seu futuro educacional, frente às pressões do capitalismo mundial em sua nova face, a neoliberal, dando enfoque à educação básica, destacando-se, assim, o Ensino Fundamental, então com oito anos, uma vez que a reforma deste mesmo nível de ensino, passando para nove 
anos, somente se efetivaria com a Lei $n^{0}$ 11.274, de 6 de fevereiro de 2006, colocada em prática pelos estados e municípios em até 2010, como previu o próprio texto legal.

Entrando em vigor em 2010, a fim de formar um grande contingente de brasileiros com no mínimo nove anos de escolaridade, o que, entre outros aspectos de interesse nacional e internacional, aumentaria o IDH do Brasil, elevando-o para médio-alto (cerca de 0,761, dado de 2019), uma vez que passariam mais tempo na escola, assim como proporcionar às crianças pobres a permanência escolar em mais um ano, pois as ricas já se encontram matriculadas em escolas privadas mesmo antes dos seis anos. Segundo Arelaro, Jacomini e Klein $(2011$, p. 38):

\begin{abstract}
$O$ argumento predominante nas justificativas do Ministério da Educação (MEC) e na documentação legislativa sobre o ensino fundamental de nove anos é que a medida garante a ampliação do direito à educação para as crianças de 6 anos de idade, em especial as pobres e excluídas do sistema educacional. Ponderou-se, naquele momento, que as crianças de 6 anos das classes média e alta já estavam matriculadas em escolas e que seria necessário incluir as classes desfavorecidas. A consideração de que as crianças de 6 anos ainda estavam fora da escola, seja pela não obrigatoriedade ou por não existir oferta de vagas suficientes na educação infantil pública, gerou um aparente consenso de que o ensino fundamental de nove anos garantiria um maior número de alunos matriculados nas escolas brasileiras e, portanto, asseguraria a essas crianças a efetivação do seu direito à educação.
\end{abstract}

O ECA - Estatuto da Criança e do Adolescente é elencado nesse estudo como a terceira legislação educacional hierarquicamente mais importante do Brasil, porém não curricular. O ECA, tendo como diretriz a Lei 8.069, de 13 de julho de 1990, que o instituiu, observada a produção e distribuição de material didático adequado, tem como prerrogativa que o currículo do ensino fundamental incluirá, obrigatoriamente, conteúdo curricular que trate dos direitos das crianças e dos adolescentes, portanto o ensino de Direitos Humanos é currículo.

Destacamos a importância do ECA não como referência curricular propriamente dita, pois, por mais que destaque esse ou aquele tópico como curricular, mas em sua transversalidade, uma vez que determina, por força de lei, que na fase compreendida como Educação Fundamental o currículo seja regido por noções que se relacionam, por exemplo, aos direitos humanos.

Os estados da federação, assim como os municípios que universalizam a educação de zero a cinco anos, a Educação Infantil, são os corresponsáveis pela manutenção do Ensino Fundamental II, cabendo aos municípios a condução da Educação Infantil, exclusivamente.

Com a criação do FUNDEB - Fundo de Manutenção e Desenvolvimento da Educação Básica e de Valorização dos Profissionais da Educação, em 1998, este deu centralidade ao Ensino Fundamental, incorporando as perspectivas do Banco Mundial, de onde veio a 
influência inspiradora para a criação do fundo que financiaria a educação nacional, e, com esse, as ideias neoliberais, especialmente as vindas do norte do planeta (Estados Unidos da América e Europa). Nessa perspectiva, Santos L. (2002, p. 2), afirma que:

[...] tem também sido demonstrado o alinhamento dessas políticas com diretrizes impostas por organismos internacionais [como a do Banco Mundial], que financiam e fornecem os critérios para as mudanças relacionadas à forma e ao conteúdo da organização e do funcionamento dos sistemas públicos de ensino, comprovando que é de disputa e rivalidades teórico-metodológicas, desde sempre (Educação Infantil), pensado o currículo escolar no Brasil.

\section{OS PARÂMETROS CURRICULARES NACIONAIS COMO PRECURSORES DA BNCC}

Arroyo (2014) vem nos apresentar formalmente a ideia de que o campo do currículo tem mostrado que as propostas pedagógicas são frutos de debates e de disputas de diferentes naturezas. Por mais coeso que seja o grupo que elabora uma proposta curricular, haverá sempre conflitos e lutas de interesse na definição de um currículo.

Quando foram lançados, em 1997, pelo então ministro da educação Paulo Renato de Sousa, do governo Fernando Henrique Cardoso, os PCN foram, indubitavelmente, construídos por mãos hábeis de especialistas da educação, mas, sob a crítica da exclusão da participação docente, do amplo chamamento público para conhecimento e chance de opinar da população na elaboração do documento, o que não houve.

Os PCN, a partir de sua publicação, se tornam documento referencial nacional do currículo para o Ensino Fundamental e, ao mesmo tempo, sem o respaldo daqueles que seriam um dos atores principais, interessados na elaboração de currículo ou de documento nacional que referenciasse o currículo, os autores de livros didáticos nacionais. Na prática do dia a dia na escola de Educação Básica, mal sabe o professor o que representa o currículo, apesar de este ser bem-intencionado.

O currículo é entendido como o que deverá ser ministrado ou colocado em prática em sala de aula, muitas vezes seguindo a lógica dos sumários dos livros, às vezes com a ação do professor, alterando-o a seu bel prazer, sem que a sequência didática e a lógica científica sejam respeitadas, não por má intenção, mas por falhas na formação pedagógica das licenciaturas, para aqueles que as possuem ou por mero desconhecimento da ciência por detrás do currículo.

Os PCN foram publicados pelo Ministério da Educação (MEC), em 1997 e introduzidos em 1998 no interior de um conjunto maior de reformas educacionais implantadas pelo Estado brasileiro (NUNES, 2012). 
Seus volumes estão divididos em: $1^{1 \underline{a}}$ a $4^{\underline{a}}$ séries e de $5^{\text {a }}$ a $8^{\underline{a}}$ séries, de modo que cada uma destas etapas possua um PCN propriamente voltado a seus objetivos e subdivididos por conteúdos curriculares - por exemplo: PCN de Geografia para a $5^{\underline{a}}$ série; PCN de Língua Portuguesa para a $8^{\underline{a}}$ série.

Nunes (2012, p. 93) traz à tona a discussão relativa ao ensino de Geografia e os PCN, ressaltando o autoritarismo do documento em sua elaboração, para a qual não houve contribuição/consulta aos profissionais da educação, e como seu ponto relevante, na falta de um currículo nacional servir como orientador da vacância curricular, assim sendo:

No âmbito da Geografia, ocorreram intensos debates sobre as proposições contidas nesse documento no tocante às falhas e lacunas do ponto de vista teórico, metodológico e mesmo didático-pedagógico. Alguns autores posicionaram-se destacando o caráter autoritário e centralizador dos parâmetros, outros apoiaram a proposta argumentando a favor da necessidade de uma orientação curricular nacional. Apesar das críticas, percebemos que os PCN têm sido apontados como referência para a elaboração de planejamentos nas escolas e mesmo para realização de avaliações do sistema escolar.

No ano de 1998 o Ensino Fundamental ainda não possuía nove anos de duração, como atualmente, tendo havido para isso devida prescrição curricular na própria LDB, tendo sido esta modificada pela Lei 11.274/2006.

Esta lei estipulou o prazo, de até o ano de 2010, para que em todas as escolas do território nacional, com crianças de todos os sistemas de ensino, acessassem o $1^{\circ}$ ano do Ensino Fundamental I, aos 6 anos de idade, modificando a duração da Educação Básica, fase do Ensino Fundamental II, para nove anos, como uma forma de que as crianças de mais baixa renda acessassem a educação básica o quanto antes, evitando-se, assim, a marginalidade escolar.

A partir da mudança no Ensino Fundamental II, que ganhara mais um ano, os PCN elaborados em 1997 para $1^{\underline{a}}$ a $8^{\underline{a}}$ série, tiveram que ser adaptados pelos educadores para $1^{\circ}$ ao 9 (anos), na medida do possível a partir dos desafios trazidos pela nova norma.

A elaboração desse tipo de documento já estava prevista na Constituição Federal de 1988, no artigo $210^{\circ}$, que estabelecia que "Serão fixados conteúdos mínimos para o ensino fundamental, de maneira a assegurar formação básica comum e respeito aos valores culturais e artísticos, nacionais e regionais". Tal premissa é reafirmada pelo artigo $9^{\circ}$ da Lei de Diretrizes e Bases da Educação Nacional (LDBEN 9.394/96) no ano de 1996.

Dessa forma, os PCN surgem com o intuito de assegurar, conforme citado, a formação básica comum e de se apresentar como um "[...] referencial de qualidade para a educação no Ensino Fundamental em todo o país" (BRASIL, 1996, p. 13), sempre frisando que esse fato se dá "na ausência da base curricular nacional", portanto, anterior a BNCC. 
Apesar disso, vale destacar que essa política educacional é permeada por uma série de polêmicas e controvérsias, além do autoritarismo sob o qual seu nascimento se deu, já destacado nesta pesquisa, sem a participação docente e da sociedade brasileira, de forma não-participativa/não-colegiada.

No que diz respeito à temática desses documentos, observamos a presença das disciplinas que tradicionalmente já pertenciam ao currículo escolar, como Língua Portuguesa, Matemática, História e Geografia e dos volumes intitulados "Temas Transversais", que se apresentavam como o grande diferencial desses materiais.

Assim, os PCN propunham atender a uma necessidade de reestruturação curricular que emergiu na década de 1980, época na qual o sistema educacional era caracterizado pela ênfase na transmissão de saberes - ao invés da necessária mediação na relação de ensino-aprendizagem - o que resultava no distanciamento entre os conteúdos escolares considerados universais ou científicos e aqueles conhecimentos trazidos pelos alunos de suas variadas origens.

Além disso, o referencial escolar - ou o que mais proximamente existia do que compreendemos como currículo - apresentava-se de maneira fragmentada, o que contribuía para o estranhamento de grande parte dos alunos para com o conhecimento trabalhado na escola, científico, colaborando com os altos índices de fracasso escolar observados à época - como as reprovações e evasões.

Nesse contexto, os Temas Transversais introduzidos pelos PCN se revelavam como alternativa de articulação dos conteúdos escolares que, se bem planejados, trariam possibilidades de acrescentar pontos positivos ao ensino, na sua dimensão mais elementar, a relação de ensino-aprendizagem.

Estas possibilidades de articulação trazida pela primeira vez pelos PCN deram às redes de ensino abertura das portas de temas como multidisciplinaridade, interdisciplinaridade e transdisciplinaridade, embora, naquele final de década de 1990, ainda considerados tabus na realidade da Educação Básica brasileira ou, no mínimo, algo exógeno. Seria necessário primeiro aprender para depois tentar sistematizar na realidade educacional carente de formação embasada na dita modernidade conceitual à qual a educação descortinava.

Os PCN prestariam um importante serviço aos sistemas de ensino, de maneira especial aos professores, auxiliando-os no processo de reelaboração curricular, buscando a construção de um documento essencial nas escolas de Educação Básica, denominado P. P. P. (Projeto Político Pedagógico), a serviço da construção da cidadania no rol das transversalidades. 
Meio Ambiente, Ética e Educação Sexual, entre outros temas transversais, facilitariam a interdisciplinaridade oferecidas aos estudantes, concomitantemente ao ensino regularcurricular proposto pelos (PCN).

Para Santos (2012), é questionável, ainda, a forma como os (PCN) foi elaborado, somente com a participação de alguns professores de escolas de Educação Básica, ficando as universidades à margem desse processo de elaboração, portanto sem contribuir com as atualizações científicas necessárias.

Também é polêmico o fato de se procurar constituir as bases para um currículo nacional a partir de um modelo que foi importado da Espanha, que veio pronto ou préfabricado e, portanto, exógeno à educação brasileira.

Aqui se adentra na discussão crítica de que a educação brasileira se utiliza recorrentemente de políticas, diretrizes e modelos internacionais, ainda que vitoriosos nos países de origem, mas que, no Brasil, pecam por desconsiderar o distanciamento destes da nossa realidade.

Embora que, para os favoráveis e para os contrários a este documento, ao concordarem em um ponto, elegem o fato de que os PCN são o documento que mais nos aproxima de uma noção, ainda que vaga, de currículo nacional, que a legislação nacional previra em 1988 com a Constituição Federal, assim conformada com a LDB de 1996, e que estaria em elaboração.

Outra crítica é que, após a publicação desses documentos, estes foram encaminhados às escolas, porém não houve a preocupação na realização de formação necessária e continuada de professores em escala nacional para que estes pudessem despertar para a importância deste documento e para os modos como os mesmos poderiam ser utilizados na realidade da sala de aula, entendendo-o na sua dimensão mais específica de vacância curricular oficial.

Entre as críticas já descritas, a seguinte, de ordem política, se faz também a este documento: "O governo FHC apresentou os PCN no âmbito de seu arsenal de propaganda institucional, sem, no entanto, definir se constituíam (apenas como) parâmetros ou (se seriam) diretrizes para a educação nacional" (SANTOS, 2012, p. 56).

A dúvida persistiu - e persiste até os dias atuais, entre educadores da escola básica, poucos sabendo, de fato, diferenciar os objetivos e/ou propostas metodológicas trazidas por esses documentos.

O professor médio de Educação Básica brasileira seria, portanto, um transmissor de conteúdo, portanto, professor conteúdista, pouco embasado em teorias e discussões acadêmico-científicas e, muito menos, teórico-metodológicas sobre assuntos diversos, inclusive sobre a necessária discussão acerca do currículo nacional e das razões que fazem com que, embora conceito fundante do ensino de Geografia no $6^{\circ}$ ano, autores optaram por 
praticamente excluir essas discussões, indo contrariamente ao que prescreviam as orientações oficias dos PCN.

Assim, a elaboração de um currículo nacional poderia privilegiar, mais uma vez, os discursos dominantes, em detrimento das classes populares, não ouvidas e até mesmo deste profissional de Educação Básica, que já se desinteressa por discursos políticos de quaisquer origens, por neles não mais acreditar.

Também se deve questionar o próprio conceito de currículo nacional, na medida em que, segundo Santos (2012, p. 55), "[...] um currículo não pode ser vivido e experimentado nacionalmente", sobretudo se levarmos em consideração as dimensões territoriais de nosso país e sua diversidade cultural. Diante disso, até mesmo a proposta de conteúdos mínimos necessita de maiores esclarecimentos. Nesse sentido, Santos vem nos dizer que:

\begin{abstract}
Se existem diferenças socioculturais marcantes, que determinam necessidades de aprendizagem diversas, existe também aquilo que é comum, no que se refere ao conteúdo que um aluno de qualquer estado do Brasil, do interior ou do litoral, de uma grande cidade ou da zona rural deve ter o direito de aprender, entende-se que esse direito deve ser garantido pelo Estado (SANTOS, 2012, p. 56).
\end{abstract}

Dessa forma, o currículo deverá contemplar todas essas diferenças para que haja uma formação educacional completa. Ainda assim, é preciso considerar a evolução das políticas públicas relacionadas à Educação Básica, que estão em andamento neste momento histórico pelo qual passa a educação brasileira, para o bem e para o mal dos processos educacionais, que aqui, nesta pesquisa, não nos propomos discutir.

A partir do governo de Michel Temer (2016-2018), foi realizada a consolidação de revisões de fundamentos e regulamentos relativos à Educação Básica que visavam a elaboração da base nacional curricular.

As referidas revisões do texto-base da BNCC, ainda que controversas e envoltas em discursos políticos a favor e contrários, foram realizadas em forma de debates, consultas e audiências públicas, nas quais houve a participação de grupos de interesse, representantes políticos, educadores e acadêmicos, bem como a sociedade civil, ou pelo menos por aquela parte que se interessou pelo debate ou que dela teve conhecimento, registre-se, pequena parte dos educadores brasileiros.

Até a propalada entrada em vigor da BNCC, os PCN constituem-se, portanto, como os únicos documentos da educação nacional atual, que, embora não tragam consigo a obrigatoriedade e força de lei - por não se constituírem como tais - trazem a necessidade de se abordar temas de relevância para o sistema educacional, e, assim, para o $6^{\circ}$ ano do Ensino Fundamental II. 
O PCN (BRASIL, 1998), sendo escrito por especialistas expoentes da educação nacional na década de 1990, recomendam, ao longo do texto, sobre como os conceitos relacionados ao espaço, lugar, território (nosso objeto), fundantes da Geografia, entre outras bases conceituais, deveriam ser trabalhados, na referência curricular brasileira, por mais fragmentada que se apresentasse naquela época, no que tange ao ensino de Geografia na escola de Educação Básica brasileira.

É certo que, paralelamente ao momento histórico da virada do milênio - nos trazendo os necessários LDB, PCN, DCN entre outros - a consolidação de ideias inovadoras no âmbito do currículo nacional, ao qual se ensejava desde 1988 com a Constituição Federal e a própria produção dos conhecimentos acadêmicos e sua distância da realidade escolar brasileira, revelavam tais orientadores do currículo, e seus primeiros e importantes passos para conquistas maiores, naquilo que o Estado brasileiro deveria produzir em termos de currículo nacional.

Dentre tais conquistas, podemos destacar a produção do conhecimento ensejada pelo ensino de Geografia, passando por várias modificações ou novas concepções pedagógicas, apresentadas pelos mais diversos teóricos nos mais variados momentos político-sociais. Quando a Geografia - independentemente de momentos históricos e tendências ideológicoconceituais - tem sua função social bem definida, os ganhos são facilmente reconhecidos pelas sociedades no que diz respeito à sua importância relacional, tanto no campo dos significados materiais e/ou simbólicos (em se tratando do binômio sociedade-natureza) e dando oportunidades para o enriquecimento de sua gama de possibilidades, que levarão à efetiva aprendizagem das visões de mundo e do mundo.

\section{O ENSINO DE GEOGRAFIA E OS LIVROS DIDÁTICOS DO 6o ANO DO ENSINO FUNDAMENTAL II}

Freitag, Motta e Costa (1997) apontam desde a metade da década de 1960 a falta de qualidade dos livros didáticos no Brasil, o que justificaria a criação do PNLD - Programa Nacional do Livro Didático, uma vez que dinheiro público é investido e deverá ser destinado a materiais que tenham compromisso, não apenas com o rigor científico, mas também com a ética e a cidadania.

Os autores argumentam que os livros didáticos até a década citada apresentavam conteúdo ideológico, presença de ideias discriminatórias, erros conceituais e insuficiência teórico-metodológica, o que fez o MEC, em 1995, instituir oficialmente a análise e avaliação pedagógica dos livros didáticos como componente da política do PNLD (FANTIN, 2013).

Em Batista (2001) e em Fantin (2013), vemos que, em 1999, foi formada uma comissão com professores especialistas e com experiência nos três níveis de ensino e, 
coordenados pela Secretaria de Ensino Fundamental do MEC, realizou-se a primeira avaliação dos livros que seriam escolhidos pelos professores de todo o país, comprados pelo governo e enviados às escolas. Muitos membros desta comissão tinham participado da avaliação piloto ocorrida dois anos antes. Cavalcanti (1998, p. 35, grifo nosso), afirma que:

Admitindo-se que o objetivo do ensino de Geografia é o de desenvolver o pensamento autônomo a partir da internalização do raciocínio geográfico, tem-se considerado importante organizar os conteúdos de ensino com base em conceitos básicos e relevantes, necessários à apreensão do espaço geográfico. A ideia é a de encaminhar o trabalho com os conteúdos geográficos e com a construção de conhecimentos para que os cidadãos desenvolvam um modo de pensar e agir considerando a espacialidade das coisas, nas coisas, nos fenômenos que eles vivenciam mais diretamente ou que eles vivenciam enquanto humanidade.

No sítio eletrônico do PNLD é possível identificar dados diversos, tais como estatísticas sobre o livro didático, quem o financia, objetivos e dificuldades a serem vencidas, uma vez que é o livro didático o recurso pedagógico mais abundante em escolas públicas e privadas, em todos os conteúdos curriculares que o currículo em 2018 engloba.

A tendência atual do PNLD, para o ensino de Geografia, é a orientação para um currículo temático e multiescalar (local, regional, nacional e global) e que possibilite leitura crítica do espaço geográfico e é papel do docente, neste cenário, escolher/elencar/eleger os temas e problematizações mais relevantes a serem analisados em relação ao espaço e às suas variáveis pois, via de regra, constituem-se de inúmeras possibilidades. Vasconcellos (1995, p. 13) vê:

[...] subjetividade do professor, ao fazer escolhas teórico-metodológicas e diz que estas sempre estarão relacionadas aos seus determinantes objetivos e subjetivos, que são formação de valores, opção ideológica, vontade política, concepção do processo do conhecimento, equipamentos, recursos didáticos como o livro adotado.

Portanto, a subjetividade do docente permeia o ensino (especificamente neste estudo) e, sendo o livro didático um dos recursos mais disponíveis, o mais usado, cabe, nesta pesquisa, a tentativa de desvendá-lo, em parte, no que tange aos conceitos relacionados ao território, na literatura didática selecionada do $6^{\circ}$ ano, não sendo encontrados os mesmos, conforme previam os PCN, enfatizando-se assim, a opção didática por não fazê-lo, até mesmo porque, poderiam os autores argumentar, com justiça, que os PCN não representavam o currículo oficial. 


\section{O OLHAR SOBRE OS LIVROS DIDÁTICOS ARARIBÁ PLUS (MODERNA) E PROJETO ATHOS (FTD), AMBOS PARA O 6 ANO/2014 - ENSINO DE TERRITÓRIO E SUAS VARIÁVEIS CONCEITUAIS}

O livro didático da coleção Araribá Plus de Geografia, 6ํano, é literatura pedagógica organizada em nove unidades temáticas e, uma vez que o ano letivo é organizado em trimestres, os planejamentos são feitos de forma que, para cada trimestre, três unidades sejam trabalhadas, e cada uma possua quatro temas - que equivalem ao significado de capítulo.

A primeira unidade, intitulada A Geografia e compreensão de mundo, traz, em suas quatro divisões, os seguintes temas: 1- Paisagem e espaço geográfico; 2- A transformação do espaço geográfico; 3- A identidade dos lugares e 4 - A compreensão do espaço geográfico. Trata-se da única unidade temática na qual aparece a palavra território, embora desprovida de seu contexto essencial, segundo os PCN.

Nesta unidade, só há essa oportunidade, em todo o 6aano, segundo o material didático, de se discutir, embora superficialmente, as noções relacionadas ao território. A palavra é literalmente citada apenas no Tema 2. Ao se abordar a transformação do espaço geográfico, as atividades econômicas e a estrutura setorial do trabalho e da economia, fazse referência à palavra território (al): "As divisões social e territorial do trabalho" (GEOGRAFIA..., 2014, p. 22). Nada mais. Os conceitos utilizados são os de lugar e paisagem, significando, algumas vezes, o que caberia ao conceito de território e suas variáveis.

Nas demais unidades - de 2 a 9 - os temas variam entre: 2 - Cartografia; 3 - O planeta Terra; 4 - Continentes e Oceanos; 5 - Relevo e hidrografia; 6 - Clima e vegetação; 7- Atividades econômicas; 8 - O espaço urbano e 9 - O espaço rural.

Também são utilizados os conceitos de lugar e paisagem, sem quaisquer referências às questões territoriais, ao território propriamente dito e sequer às suas variáveis, que trariam coerência com o que diz os PCN, enquanto pré-orientador do currículo nacional.

O material da literatura didática da Editora Moderna, portanto, não está totalmente em consonância com o que diz os PCN para o 6ำ ano da Educação Fundamental 2, ou, ainda, para o $3^{\circ}$ ciclo, que engloba, segundo os PCN, o $5^{\circ}$ e $6^{\circ}$ anos.

As concepções relacionadas ao espaço, como categoria conceitual, trazem consigo a noção de espaço alterado e que sofreu a ação antrópica, dividindo-se entre natural, no qual o impacto humano é mínimo, e o espaço geográfico (antropizado por excelência).

Quando são abordados conceitos relativos às transformações das paisagens pelas forças produtivas humanas, devido à Revolução Técnico-científica e Informacional, fica clara a tendência da Editora Moderna de usar conceitos relacionados ao autor Milton 
Santos, com seis títulos citados na bibliografia de Araribá Plus, portanto, o autor mais citado como referencial teórico. Segundo Santos M. (2002, p. 16), é "[...] por demais sabido que a principal forma de relação entre o homem e a natureza, ou melhor, entre o homem e o meio, é dada pela técnica".

As referências indiretas à questão multiterritorial, embora essa palavra jamais seja mencionada na obra, é sugerida com "Os espaços ocupados pelos seres humanos constituem o objeto de estudo da Geografia: espaço geográfico, construído e reconstruído permanentemente pelo trabalho humano e pela natureza" (GEOGRAFIA..., 2014, p. 19).

Ao se trabalhar as atividades econômicas e as forças transformadoras presentes nas ações humanas gerando riquezas, assim como na divisão social e territorial do trabalho e desigualdades sociais e econômicas, há clara tendência materialista-marxista, embora também não haja quaisquer referências a Karl Marx no referencial bibliográfico.

Conforme encontramos em "As divisões social e territorial do trabalho", temos que "O trabalho do ser humano é considerado social, pois atende às necessidades da sociedade para a sua manutenção" (GEOGRAFIA..., 2014, p. 22). Portanto, o ser humano é mostrado como sujeito da construção material da sociedade, conforme encontramos validação em Lukács (1978, p. 8):

No trabalho, ao contrário, o ser-para-nós do produto torna-se sua propriedade objetiva realmente existente: e trata-se precisamente daquela propriedade em virtude da qual o produto, se posto e realizado corretamente, pode desempenhar suas funções sociais. Assim, portanto, o produto do trabalho tem um valor (no caso de fracasso, é carente de valor, é um desvalor). Apenas a objetivação real do ser-para-nós faz com que possam realmente nascer valores.

Por sua vez, o conceito de lugar, relacionado à concepção geográfico-simbólica, presente em Criando ligações identitárias, é trazido como se o conceito de território em cada "[...] indivíduo se relaciona[se] de forma diferente com os lugares de acordo com os significados que [este] dá a eles" (GEOGRAFIA..., 2014, p. 27).

Finalizada a primeira unidade da obra Araribá Plus, o que acontecerá na página 37, não há referência, em quaisquer outras partes do livro, ao conceito de território e às suas variáveis conceituais. No máximo, faz-se analogia ou sugerem-se conceitos relacionados ao lugar e à paisagem.

A obra possui 273 páginas - considerando o livro do professor e o manual, este incluído como material anexo - e nove unidades. Cada unidade possui quatro temas equivalentes aos capítulos e apenas uma delas, ou seja, a primeira, refere-se uma única vez, diretamente, ao conceito de território, sem os significados variáveis que lhe são pertinentes, muito menos observam-se conceitos que se desdobram de território em 
territorialidade. No máximo, o que se faz é usar lugar, região e paisagem como categorias geográficas sinônimas para o conceito de território e vice-versa.

A obra do $6^{\circ}$ ano do Ensino Fundamental 2, Projeto Athos (das autoras Castellar e Saferian) também é dividida em nove unidades, como feito na obra Araribá Plus, mais uma vez sugerindo a divisão trimestral adotada pelas escolas das redes sobre as quais este estudo foi realizado, em que, a cada trimestre, três unidades e seis capítulos são trabalhados.

Cada unidade temática possui subdivisão em capítulos, e cada uma das unidades contém dois capítulos e não quatro, como na obra Araribá Plus, porém estes são mais densos e de embasamento histórico, ao contrário do livro da Editora Moderna, o que, na prática, faz com que o tempo gasto com o desdobramento do currículo seja extenso nas duas obras.

Por sua vez, o Projeto Athos contém 63 páginas do manual anexo ao livro do professor e 224 páginas do livro didático propriamente dito, perfazendo 287 páginas analisadas. As unidades são assim definidas: 1 - Localização e orientação; 2 - A Terra e o universo; 3 - Apresentação do espaço; 4 - Dinâmica interna da Terra; 5 - Dinâmica externa da Terra; 6 - Paisagens; 7- Planeta Terra: tempo e clima; 8 - Planeta Terra: água e 9 - A ação antrópica.

No manual de orientação, que consta das páginas introdutórias do livro destinado ao professor e às quais o estudante não tem acesso, há um texto no qual, ao se afirmar a dimensão da metodologia de ensino, que envolve "[...] uma bem elaborada conceituação de território -enquanto Estado-nação, [...] associando-se também (o território) à ideia de poder" (CASTELLAR; SEFERIAM, 2014, p. 31).

Essa noção, acima descrita, estaria em conformidade com as teorias de Raffestin (1993), autor relacionado ao aspecto materialista do conhecimento geográfico com noções vinculadas aos conceitos de território estudados no $6^{\circ}$ ano, embora não esteja este autor relacionado na bibliografia da obra e nem em quaisquer outras partes do material didático: Projeto Athos.

Mais uma vez as questões conceituais territoriais estão diluídas em conceitos rasos como o de lugar e paisagem, não sendo desenvolvidos, como esperado, no 6ำ ano da educação básica, devido ao fato de serem conceitos fundantes ou principais no ensino de Geografia na educação básica, em especial no Ensino Fundamental 2.

Portanto, a palavra território e os conceitos que esta enseja não aparecerão na obra citada. Estes sequer são tratados ou mencionados, abrindo-se, então, um vazio que dissona dos objetivos da educação básica e no ensino de Geografia do 6ํano, trazendo à tona a lacuna conceitual que poderá comprometer a assimilação concernente ao território e suas variáveis, ao longo desta etapa educacional. 
O Projeto Athos é organizado em dois capítulos por unidade, sendo assim definidas as suas estruturas: 1 - Localização e orientação; 2 - A Terra e o universo; 3 - Apresentação do espaço; 4 - Dinâmica interna da Terra; 5 - Dinâmica externa da Terra; 6 - Paisagens; 7Planeta Terra: tempo e clima; 8 - Planeta Terra: água e, por fim, 9 - A ação antrópica.

São, portanto, nove unidades e 18 capítulos a serem trabalhados durante o ano letivo. Embora presente no manual de utilização que consta das páginas introdutórias do livro destinado ao professor (e ao qual os estudantes não têm acesso), há um texto no qual se afirma a dimensão da metodologia de ensino a que se propõe o material didático, e que envolve uma bem elaborada conceituação de território, enquanto Estado-nação, "[...] associando-se também à ideia de poder" (CASTELLAR; SAFERIAN, 2014, p. 31), mas não é exatamente isso que a análise do conteúdo nos revelou.

\section{CONCLUSÕES}

Das 560 páginas dos dois textos dos livros didáticos analisados, que constituíram o banco de dados deste estudo, Araribá Plus e Projeto Athos, ambos para o 6ำ ano do Ensino Fundamental 2, ficou evidenciado o fato de que a discussão acerca dos objetos espaço-territoriais, e, especialmente, os territoriais, conforme nosso objeto, de acordo com o que preconizam os PCN, não estão presentes nas obras, pelo menos não da forma como este documento propõe em sua função de oferecer e orientar o que entendemos como currículo no ano de 2018, indicando como fundamentalmente necessário na formação deste início do pensamento de caráter complexo, já esperado, no transcorrer do 6ํano, as concepções concernentes ao território, que os livros não trazem da forma como preveem os PCN desde o final da década de 1990.

Embora não sejam os (PCN) a representação do currículo oficial, mas o único indicador de currículo nacional existente no Brasil antes da entrada em vigor da BNCC em 2019, afirmamos que não foram seguidos, conforme o MEC e o governo federal sugerem ao colocar este documento em vigor em 1997 e, desde então, os livros didáticos praticamente os ignoram, forjando seus próprios currículos nacionais, deliberada ou displicentemente.

Concluímos que são apresentados poucos conceitos concernentes ao território, nos livros didáticos analisados neste objeto de pesquisa, sob o viés de acepção materialista teórico-metodológico, não existindo abordagens, somente uma e muito rasa, proveniente do simbolismo acadêmico-geográfico, em mais de 500 páginas.

As abordagens perceptíveis são aquelas influenciadas por Milton Santos, direta e indiretamente, respondendo à hipótese levantada por este trabalho. Indireta, quando os autores o parafraseiam no transcorrer dos textos dos livros didáticos, ainda que sem citá-lo 
formal e diretamente, porém referenciando-o na bibliografia, o autor mais citado, em ambas as obras.

A princípio, questionamos se seriam os livros didáticos, objetos desta pesquisa, assim como seus autores, orientados pelo materialismo ou se pelo simbolismo geográfico. Durante o trânsito desta pesquisa confirmamos ser o materialismo o ordenamento maior presente nos livros didáticos e ainda constatamos que a Geografia de cunho simbólico ainda está praticamente restrita às discussões acadêmicas, não alcançando os saberes da Geografia escolar, pelo fato de ser o próprio estudo e ensino deste conteúdo curricular de viés simbólico, recente no mundo e, mais ainda, em nosso país - ainda que os PCN já se refiram a este sentido/viés indicando-o mais que necessário. Não o encontramos nas literaturas didáticas e nem nas expressões e conceitos técnicos propostos.

A análise dos dados nos permite constatar que não se trata apenas do que se ensina, mas como se ensina Geografia nas escolas de Educação Básica, Brasil afora, e, também, quais seriam as abordagens, sentidos e abrangências, sendo estas provenientes do campo do materialismo dialético, pois assim foi toda uma geração de geógrafos formados sob a batuta do maior geógrafo brasileiro, Milton Santos, e entender que a discussão da Geografia simbólica precisa irromper os muros da academia e chegar à sala de aula, com professores bem formados em teoria e métodos de ensinar-aprender.

Milton Santos é a nossa grande constatação, enquanto pesquisadores de tendências e abordagens do ensino de Geografia no Brasil via livros didáticos, de viés materialista, portanto justificando a opção por discussões acerca da luta de classes, profundamente materialista e de inspiração marxista, como o próprio sempre fez questão de deixar claro em sua literatura de projeção mundial.

\section{REFERÊNCIAS}

ARELARO, Lisete Regina Gomes; JACOMINI, Márcia Aparecida; KLEIN, Sylvie Bonifácio. O ensino fundamental de nove anos e o direito à educação. Educação e Pesquisa, São Paulo, SP, v. 37, n. 1, p. 35-51, 2011.

ARROYO, Miguel Gonzales. Currículo, território em disputa. Petrópolis: Vozes, 2014.

BATISTA, Antônio Augusto Gomes. Recomendações para uma política pública de livros didáticos. Brasília: MEC/SEF, 2001. Disponível em: http://www.dominiopublico.gov.br/download/texto/me002406.pdf. Acesso em: 21 jan. 2016.

BRASIL. [Constituição (1988)]. Constituição da República Federativa do Brasil. Brasília, DF: Congresso Nacional, 1988.

BRASIL. Lei 9.394, de 20 de dezembro de 1996. Estabelece as Diretrizes e Bases da Educação Nacional. Brasília, DF: Congresso Nacional, 1996.

BRASIL. Parâmetros curriculares nacionais: introdução aos parâmetros curriculares nacionais do Ensino Fundamental II. Brasília: MEC/SEF, 1998. 
CASTELLAR, Sonia Maria Vanzella; SEFERIAN, Ana Paula Gomes. Geografia 60 ano. São Paulo: FTD, 2014.

CAVALCANTI, Lana de Souza. Geografia, escola e construção do conhecimento. Campinas: Papirus, 1998.

FANTIN, Maria Eneida. Análise e produção de textos didáticos para o ensino de geografia. Curitiba: InterSaberes, 2013.

FREITAG, Barbara; MOTTA, Valéria Rodrigues; COSTA, Wanderly Ferreira da. 0 livro didático em questão. São Paulo: Cortez, 1993.

GEOGRAFIA do 6 ano. São Paulo: Editora Moderna, 2014. (Coleção Projeto Araribá Plus: Geografia 6).

KRAMER, Sonia. Propostas pedagógicas ou curriculares: subsídios para uma leitura crítica. Educação \& Sociedade, Campinas, v.18, n. 60, p. 12-15, dez. 1997.

LUKÁCS, Georg. As bases ontológicas do pensamento e da atividade do homem. São Paulo: Ciências Humanas, 1978. (Temas de Ciências Humanas, v. 4, p. 1-18).

NUNES, Flaviana Gasparotti. Professores e Parâmetros Curriculares Nacionais (PCN): como está essa relação? RA' E GA: O Espaço Geográfico em Análise, Curitiba, PR, v. 24, p. 92-107, 2012.

PINTO, Rosângela de Oliveira; PIZZIRANI, Flávia. Legislação educacional. Londrina: Educacional, 2017.

RAFFESTIN, Claude. Por uma geografia do poder. São Paulo: Ática, 1993.

SANTOS, Lucíola Licínio de Castro Paixão. Políticas públicas para o ensino fundamental: parâmetros curriculares nacionais e sistema nacional de avaliação (SAEB). Educação \& Sociedade, Campinas, SP, v. 23, n. 80, p. 7-11, 2002.

SANTOS, Milton. Por uma geografia nova: da crítica da geografia a uma geografia crítica. São Paulo: EdUSP, 2002.

SANTOS, Pablo Silva Machado Bispo dos. Guia prático da política educacional no Brasil: ações, planos, programas e impactos. São Paulo: Cengage, 2012.

VASCONCELLOS, Celso dos Santos. A construção do conhecimento em sala de aula. São Paulo: Libertad, 1995.

Recebido: março de 2020. Aceito: junho de 2020. 